\title{
Re-examining death: against a higher brain criterion
}

\author{
Josie Fisher University of New England, New South Wales, Australia
}

\begin{abstract}
While there is increasing pressure on scarce health care resources, advances in medical science have blurred the boundary between life and death. Individuals can survive for decades without consciousness and individuals whose whole brains are dead can be supported for extended periods. One suggested response is to redefine death, justifying a higher brain criterion for death. This argument fails because it conflates two distinct notions about the demise of human beings - the one, biological and the other, ontological. Death is a biological phenomenon. This view entails the rejection of a higher brain criterion of death. Moreover, I claim that the justification of the whole brain (or brain stem) criterion of death is also cast into doubt by these advances in medical science. I proceed to argue that there is no need to redefine death in order to identify which treatments ought to be provided for the permanently and irreversibly unconscious. There are already clear treatment guidelines.
\end{abstract}

(Fournal of Medical Ethics 1999;25:473-476)

Keywords: Bioethics; brain death; death; persistent vegetative state

\section{Introduction}

Advances in medical science have blurred the boundary between life and death. Death has come to be regarded as a process rather than a single event when all of the characteristics associated with life cease. The traditional signs of life can now be artificially maintained. Individuals who can never regain consciousness can survive for decades, and individuals whose whole brains are dead can be supported for extended periods. ${ }^{1}$ At the same time, there is increasing pressure on health care resources in circumstances of scarcity.

It has been claimed that there is a practical and moral necessity to re-examine the concept or definition of death. This task is primarily philosophical. From the definition of death, criteria and tests for death can be logically derived. This is primarily an empirical task. ${ }^{2}$ It is widely agreed that some form of philosophical reflection is presupposed in all definitions of death. For example, Dallas High claims that: “... the question regard- ing death is often posed in the following way: what is essential to the nature of man the loss of which would warrant calling an individual dead?" 3 The answer to this question, he claims, is primarily philosophical. Others have claimed that there are three conceptual levels inherent in any definition of death: first, the philosophical question of what it means for a human being to die - this concerns the concept or definition of death; second, the medical questions concerning the criteria for determining death, and third, the diagnostic problems to do with determining whether the criterion has been met. ${ }^{4}$ Similarly it has been argued that "[a]ny formulation of death has three components: a concept or definition of what it means to die; operational criteria for determining that death has occurred; specific medical tests showing whether or not the criteria have been fulfilled". 5 The first component is chiefly philosophical while the second and third components are medical.

\section{The concept or definition of death}

Discussions about death are often unclear and confused. This is partly because biological and ontological notions are conflated. I argue that a distinction between the biological and ontological demise of human beings is essential for making clear the competing views about the concept or definition of death. ${ }^{6}$ Death, traditionally understood, is something that "happens" to biological organisms. Persons, however, can lose that which is essential to their existence without biological death occurring.

Traditionally, death has been defined as "the loss of that which is necessary for the organism to continue to function as a whole...". ${ }^{7}$ Death, on this view, is diagnosed when the body's vital functions cease. The criterion of death, on this traditional view, is the loss of heart and lung function, since continued integrated functioning of the organism as a whole was impossible after these organs failed.

Currently, in most developed countries, death can be diagnosed when the whole brain, including the brain stem, ceases to function. The claim is 
that heart and lung function is not, in itself, what is essential for integrated life; rather, loss of these capacities provides evidence that brain death has occurred. Once the whole brain ceases to function, the other organs necessarily fail. The brain is taken as the vital organ on which integrated functioning depends rather than the heart and lungs. This means that either the cardiorespiratory criterion or the whole brain criterion must be met before death can be diagnosed. The definition of death, however, is still the loss of that which integrates the functioning of the organism as a whole.

Some thinkers argue that a higher brain (or neocortical) criterion for death ought to be adopted. This view is justified by the claim that "... conceptually we should be interested in loss of the functions of consciousness and personality, and ... a whole-brain rather than a higher-brain criterion should be used only because we are not sufficiently certain which higher brain areas are necessary for these functions, and we prefer to err on the side of safety". ${ }^{8}$ Supporters of this position argue that as soon as widely available tests can accurately confirm that the part of the brain necessary for consciousness has been destroyed, a higher brain criterion of death should be adopted.

This is a controversial position. It challenges the traditional concept or definition of death. According to proponents of the higher brain criterion of death, death is defined "as the loss of that which is essentially significant to the nature of the organism". ${ }^{7}$ On this view some human beings able to breathe and maintain heart function unassisted would meet the criterion for death.

I claim that life and death are mutually exclusive concepts, death cannot be redefined to include human beings who have integrated biological life. Implicit in this claim is the rejection of a higher brain criterion for death. Moreover, I claim that the justification of the whole brain (including the brain stem) criterion for death is also cast into doubt by advances in medical science.

\section{Unconscious life, not death}

Consider the following examples. First, there was no dispute about whether Karen Ann Quinlan would ever regain consciousness or whether she would ever be able to return to a life that was in any sense normal (have a job, a family, go on holidays, and so on). She was in a persistent vegetative state and connected to a respirator. The respirator was disconnected in the expectation that she would die, however, she continued to breathe unassisted and survived for a further ten years in this state. ${ }^{9}$ What this proved was that she had a functioning brain stem. What it did not demon strate was that her continued life had any value form her. Quinlan fulfilled the higher brain criterion of death.

Second, there was no dispute about Trish Marshall's condition. Marshall was shot whilst involved in a robbery in San Francisco in 199娄 She was declared brain dead two days later. YêE “... a respirator maintained her breathing, he heart was beating, her body was warm, and he bodily functions were continuing". ${ }^{10}$ The reason for this treatment was that she was seventee? weeks pregnant and her parents and the supposed father wanted everything possible done to save the fetus. This treatment continued for 105 days, afte⿸丆口 which the baby was delivered by caesarean section and survived. ${ }^{10}$ There is no straightforward way Marshall could have benefited from this treatmenits (except in the sense that she may have desired that everything possible be done to ensure her fetus survived). Marshall fulfilled the whole brain criterion of death (and, thereby, the higher brain crite rion of death).

One way to deal with these examples is to clair that permanent and irreversible loss of conscious ness is equivalent to death, that is, redefin death. ${ }^{11}$ Such a move, however, is counterintuitôf Integrated, biological functioning continued ie both women. The only difference between conditions was that Marshall's brain stem fưne tion was replaced by intensive care medicine, ena bling the integrated functioning of her body to continue, while Quinlan's brain stem coula integrate this functioning. Unless there is morally relevant difference between artificially maintained integrated functioning and natural maintained integrated functioning, the morai considerability of the two individuals is the sam I believe that there is not. Consider an analog There is an individual whose life depends on pacemaker regulating his or her heartbeat. Can $\mathbf{g}$ be seriously argued that this individual's morat standing is affected by his or her dependence o the pacemaker for continued life?

While the traditional signs of life can be artificially maintained, I believe that it is a mistake to claim that advances in medical science requirise a new answer to the question: "what is death? Advances in medical science have challenged us to reassess what it is that we value about life and what the harm of death consists in. Barbara Levenboo for example, claims that the harm in death comes primarily from the loss of experiencing ${ }^{12}$ and, as Frances Kamm points out, the loss “... of those goods of life whose loss makes death so bad can b $\vec{g}$ lost without death, making life without them no better than death. Consciousness ... seems a prime 
candidate for a good for whose loss death is not necessary and whose permanent loss is as bad as death". ${ }^{13}$ Kamm does not claim that permanent loss of consciousness is equivalent to death; rather, it is as bad as death. This state is as bad as death since death is not an additional harm to the individual, but this state is not equivalent to death since biological death is yet to occur. If, on the other hand, death is not a harm but a benefit (for example, because the individual was in unbearable pain), then the benefit accrues when consciousness is permanently lost, there is no additional benefit when death occurs.

The important and pressing ethical question does not turn on whether the concept or definition of death ought to be re-examined. Nor does it turn on the distinction between artificially maintained integrated biological functioning and naturally maintained integrated biological functioning, in the absence of consciousness. The important and pressing question is: "what ethical constraints apply to the treatment of those who can never (again) be conscious?".

\section{Treating the permanently and irreversibly unconscious}

Individuals who are permanently and irreversibly without consciousness are in persistent vegetative states. Quinlan was in this state. Anencephalic infants are also in this state since they lack the capacity ever to become conscious. Individuals who, like Marshall, have their biological life extended after whole brain death has occurred, are also permanently and irreversibly unconscious. These individuals are biologically alive and are within the health care system. The permissible treatment of these individuals is constrained in the same way that the provision of medical treatment for other patients is constrained.

First, the principle of informed consent constrains permissible treatment in a health care context. It is widely agreed that individuals may permissibly refuse life-saving or life-extending treatment. If someone has made it clear (through an advance directive or a living will, for instance) that they do not want biological life extended in the permanent absence of consciousness, then it would be impermissible to do so.

Second, the provision of treatment that cannot benefit the individual is not ethically required. No currently available treatment can improve the condition of these individuals so treatment is not ethically required. Further, it could be argued that in conditions of scarcity not every treatment that would benefit an individual can be provided, therefore it would be impermissible to provide treatment for someone who cannot benefit.
In practice individuals in persistent vegetative states receive different treatment from individuals who, like Marshall, fulfil the whole brain criterion for death. ${ }^{14}$ The latter may have biological life maintained for specific reasons - to allow a fetus to develop or to maintain organ integrity before removal for transplantation, for example. It is not, however, considered to be ethically required to do so indefinitely or without reason. The position I argue for requires a reassessment of the treatment provided for patients who are in persistent vegetative states. These patients can survive for decades in this state. I argue that there is no morally relevant difference between individuals in persistent vegetative states and those who meet the whole brain criterion of death and whose biological lives could be extended.

Third, no treatments that fall into the category "extraordinary" are ethically required. Although there is dispute about just which treatments fall into this category, my claim is that whatever they are, they need not be provided for those who are permanently and irreversibly unconscious. For instance, if the provision of a feeding tube is considered extraordinary, then there is no ethical requirement to provide it for these patients.

\section{Conclusion}

Advances in medical science have made it possible for biological life to be extended in the absence of consciousness. This has led some thinkers to argue that the concept or definition of death needs to be re-examined. They argue that the permanent and irreversible loss of consciousness is equivalent to death. This position cannot be defended. What medical science has made possible is continued non-conscious life. "Life without conscious experience may be meaningless, possibly futile, but it does not amount to death."15

One motivation for redefining death is that decisions have to be made about the medical treatments provided for individuals who are in a permanent and irreversible state of unconsciousness. The resource implications of maintaining these patients for extended periods are significant. If it could be successfully argued that they are dead, then no medical treatment is ethically required.

I offer an alternative approach. What I suggest is to focus on those capacities that an individual has lost, rather than those capacities the individual retains. This position recognises the role of the capacity for consciousness in a meaningful life. When this capacity is irreversibly lost, continuing biological functioning is of no value to the individual. Individuals in this condition include those in persistent vegetative states (those who 
need artificial ventilation and those who do not), anencephalic infants, and those who meet the whole brain criterion of "death" though biological life can be maintained.

I do not claim that these patients are dead, nor do I claim that they have no moral standing. What I do claim is that patients in these groups have the same moral standing and that there are constraints on the permissible treatment of these individuals. They have biological life and they are in the health care context. There are clear guidelines concerning treatment options in this context.

Fosie Fisher BA, DipHum, PhD(NE), is Lecturer in Business Ethics, Department of Marketing and Management, University of New England, New South Wales, Australia.

\section{References and notes}

1 Singer P. Rethinking life and death. Melbourne: The Text Publishing Company, 1994: 31. See also Rowland TW, et al. Brain death in the paediatric intensive care unit. A clinical definition. American fournal of Diseases of the Child 1983;137:547-50 and
Anstötz C. Should a brain-dead pregnant woman carry h\& child to full term? The case of the 'Erlangen baby'. Bioethiff 1993; 7:4:340-50.

2 Lamb D. Organ transplants and ethics. London: Routledg? 1990: 26-7.

3 High DM. Death, definition and determination of: conceptual foundations, philosophical and theological foundations. If Reich WT, ed in chief. Encyclopedia of bioethics. New York: Th Free Press, 1978: 301.

4 Truog RD, Fletcher JC. Brain death and the anencephaf newborn. Bioethics 1990;4:3:203.

5 Bartlett ET, Younger SJ. Human death and the destruction the neocortex. In Zaner RM, ed. Death: beyond whole-brain c teria. Dordrecht: Kluwer Academic Publishers, 1988: 200.

6 The terms "biological definition of death" and "ontologici definition of death" are used by David Lamb. See reference 2 44.

7 Downie J. Brain death and brain life: rethinking the connection Bioethics 1990;4:3:217.

$8 \mathrm{Kamm}$ FM. Morality, mortality volume I: death and whom to sas from it. New York: Oxford University Press, 1993: 203.

9 Peter Singer remarks that this is a "famous case". See referen 1: 70 .

10 See reference 1: Singer: 9 .

11 It should be noted that these two examples are not unique: chose them simply because they are well known.

12 Levenbook BB. Harming someone after his death. Ethics 198 94:413

13 See reference 8: 18-19.

14 See for example, Pallis C, Harley DH. ABC of bainstem dea London: BMJ Publishing Group, 1996

15 Lamb D. Death, brain death and ethics. London: Croom Helnm 1985: 92

\section{News and notes}

\section{Project on Death in America}

The Project on Death in America, funded by the Open Society Institute, a non-profit foundation that supports the development of open societies worldwide, invites health care professionals to submit applications to its Faculty Scholars Program. This program supports scholars who are committed to improving the care of the dying through initiatives in research, scholarship, education and policy.

Applications are requested from all relevant US health care professionals (physicians, nurses, social workers, lawyers, those providing pastoral care or ethicists) who are doctorate-level faculty members from accredited health professional educational institutions in the United States and hold the rank of Instructor, Assistant or Associate Professor.

The application deadline is January 6, 2000 .

For applications or more information please call; (617) 632-6190 or e-mail jerry_garcia@dfci.harvard.edu 